\title{
SUDDEN NATURAL DEATH DUE TO RUPTURE OF AORTIC DISSECTION AN AUTOPSY STUDY OF 15 CASES
}

\author{
Rajeev V. M1, Jinesh P. S², Deepu T33, Neethu M. Babu ${ }^{4}$ \\ ${ }^{1}$ Associate Professor, Department of Forensic Medicine, Government Medical College, Kottayam, Kerala. \\ ${ }^{2}$ Senior Lecturer, Department of Forensic Medicine, Government Medical College, Kottayam, Kerala. \\ ${ }^{3}$ Senior Resident, Department of Forensic Medicine, Government Medical College, Kottayam, Kerala. \\ 4 Junior Resident, Department of Forensic Medicine, Government Medical College, Kottayam, Kerala.
}

\section{ABSTRACT}

Present study is a retrospective study conducted in the Department of Forensic Medicine, Government Medical College, Kottayam, during a period of 5 years from 03-01-2010 to 14-07-2015. During the above period, there were 15 cases of sudden death due to aortic dissection brought to Dept. Forensic Medicine, for autopsy. Post mortem was conducted by the modified Rokitansky method and the findings were noted. Objectives of our study were to determine the 1. Etiological factors leading to aortic dissection, 2. Study the distribution of age and sex groups in the incidence of aortic dissection and 3. To study the pattern and incidence of various pathological types of aortic dissection.

\section{KEYWORDS}

Aortic Dissection, Sudden Natural Death, Autopsy.

HOW TO CITE THIS ARTICLE: Rajeev VM, Jinesh PS, Deepu T, et al. "Sudden natural death due to rupture of aortic dissection an autopsy study of 15 cases." Journal of Evolution of Medical and Dental Sciences 2015; Vol. 4, Issue 103, December 24;

Page: $16886-16889$, DOI: $10.14260 /$ jemds/2015/2540

\section{INTRODUCTION \\ REVIEW OF LITERATURE}

Aorta is conduit through which the blood ejected from the left ventricle of the heart is delivered to the systemic arterial bed. Normal diameter at the origin $=3 \mathrm{~cm} ; 2.5 \mathrm{~cm}$ at the descending part of thorax; 1.8 to $2 \mathrm{~cm}$ in the abdomen. ${ }^{1}$

\section{Aorta consists of 3 layers; from within outwards}

1. Intima (Thin lining composed of endothelium, subendothelial connective tissue and internal elastic lamina).

2. Tunica media (Thick media composed of smooth muscle cells and extra-cellular matrix).

3. Adventitia (Composed of connective tissue enclosing the vasa-vasorum and nervi vascularis). ${ }^{1,2}$

\section{DISEASES OF AORTA}

1. Aortic aneurysm.

2. Aortic dissection.

3. Aortic occlusion. 1,3

\section{AORTIC DISSECTION}

Is a catastrophic illness characterized by dissection of blood along laminar planes of the Aortic media with the formation of a blood filled channel within the aortic wall that often ruptures causing massive haemorrhage. It is caused by a circumferential or transverse tear of the intima. ${ }^{1,4}$

\section{COMMON SITES}

1. Right lateral wall of ascending aorta where the hydraulic shear stress is high.

Financial or Other, Competing Interest: None.

Submission 30-11-2015, Peer Review 01-12-2015,

Acceptance 18-12-2015, Published 24-12-2015.

Corresponding Author:

Dr. Rajeev V. M,

Associate Professor,

Department of Forensic Medicine,

Govt. Medical College

Kottayam.

E-mail: drrajeevvm3056@gmail.com

DOI:10.14260/jemds/2015/2540
2. Another common site is the descending thoracic aorta just below the ligamentum arteriosum.1,5

\section{DEBAKEY CLASSIFICATION OF AORTIC DISSECTION. ${ }^{6}$}

Type 1: Intimal tear in ascending aorta, but which involves descending aorta as well.

Type 2: Intimal tear limited to ascending aorta alone.

Type 3: Intimal tear is in the descending aorta with distal propagation of dissection.

\section{STANFORD CLASSIFICATION.1,5}

Type A: Involves ascending aorta.

Type B: Involves descending aorta.

Type A is more dangerous than type B.

\section{ETIOLOGY}

1. Systemic hypertension.

2. Cystic medial necrosis (Marfan and Ehler Danlos syndrome).

3. Inflammatory aortitis (Takayasu disease and Giant cell).

4. Congenital aortic valve anomalies.

5. Coarctation of aorta.

6. Pregnancy (3rd trimester).1,5,6

\section{SEX INCIDENCE}

Male:Female: 2:11

Age Incidence: $6^{\text {th }}$ and $7^{\text {th }}$ Decade more common. ${ }^{1,7}$

\section{CLINICAL FEATURES}

1. Sudden onset of pain (Localized to front or back of chest, Inter-scapular pain and migrates with propagation of dissection.

2. Syncope, Dyspnoea, Weakness.

3. Hypertension/Hypotension, loss of pulse, aortic regurgitation, pulmonary oedema.

4. Neurologic findings-Hemiplegia and paraplegia.

5. Myocardial infarction, bowel ischaemia, haematuria. 
6. Due to compression-Horner's syndrome (Superior Cervical Ganglia), SVC syndrome, Hoarseness, Dysphagia, Dyspnoea. 1,5

\section{COMPLICATION}

Aortic Regurgitation (Most Common).

\section{INVESTIGATIONS}

1. Chest x-ray shows wide superior mediastinum and leftsided pleural effusion.

2. ECG-No evidence of ischemia helps to distinguish between MI and aortic dissection.

3. Diagnosis established by aortography, CT/MRI, transesophageal echocardiography. ${ }^{1,5,6}$

\section{TREATMENT}

1. Beta-blockers, Calcium channel blockers.

2. Surgical-preferred for ascending aortic dissection type A and complicated type B dissection.

3. Excision of intimal flap, obliteration of false lumen, placement of an interposition graft.

4. Endo luminal stent graft for type B.

5. Follow up for every 6-12 months with contrast CT/MRI.1,5

\section{MATERIALS AND METHODS}

We studied (Retrospective study) 15 cases of sudden death due to aortic dissection over a period 03-01-2010 to 14-072015 brought to Dept. of Forensic Medicine, Govt. Medical College, Kottayam for postmortem examination. History and relevant facts were collected from the inquest paper and by questionnaires to the relatives, which are documented in the tabular form as proforma. A total of 15 cases were studied, out of which one was an "Unknown" body and hence the detailed history could not be taken.

\section{AUTOPSY FINDINGS}

At autopsy, we observed the following findings in addition to general examination findings:

1. Aortic root dilatation (Root diameter), Atherosclerotic changes.

2. Type of dissection and site of rupture.

3. Weight of heart, thickness of ventricles, measurements of valves, mitral valve prolapse, dilatation of ventricles, changes in myocardium, patency of coronary arteries.

\section{DISCUSSION OF RESULTS}

There were 3 cases (20\%) in the age group of 20-30, 2 cases $(13 \%)$ in the age group of $31-40,2$ cases $(13 \%)$ in the age group of 41-50, 1 case (7\%) in the age group 51-60, 3 cases (20\%) in the age group $61-70$ and 4 cases $(27 \%)$ in the age group above 70 . That means 5 cases in the age group of below 40,10 cases in the age group of above 40 . This shows that age has a positive correlation in cases of death due to rupture of aortic dissection. Majority (73\%) of the cases was males and 4 (27\%) cases were females. From among the 4 females, none of them were pregnant.

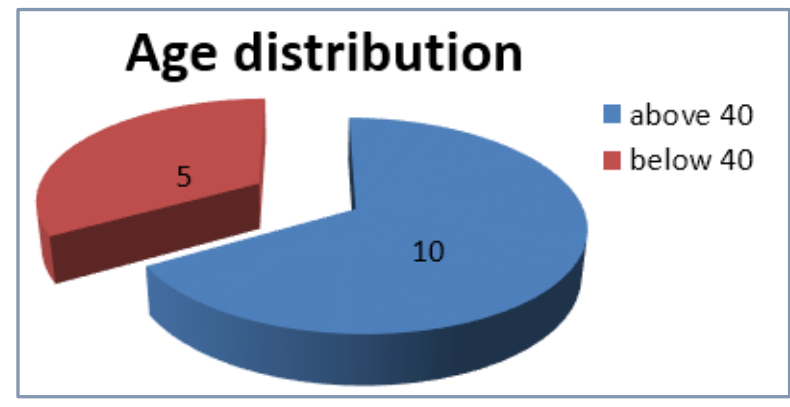

Fig. 1: Distribution of age among the Study Population

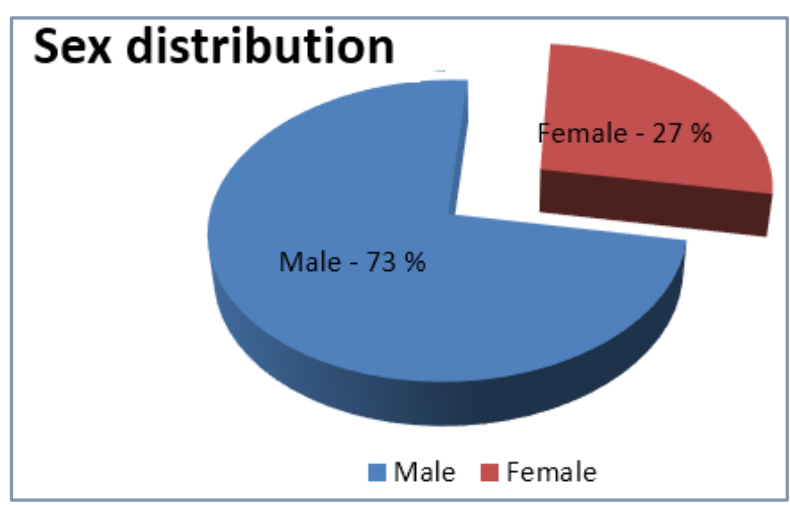

Fig. 2: Distribution of sex among the Study Population

From the total number of cases, the height of majority of the cases ranged between $151-165 \mathrm{cms}$. Weight of a great majority of the cases were below $68 \mathrm{kgs}$. The BMI revealed that $4(27 \%)$ were underweight, $6(40 \%)$ have normal weight, 2 $(13 \%)$ were overweight and $3(20 \%)$ of the cases were obese. So, underweight or overweight/obesity cannot be considered as a factor contributing to death due to aortic dissection.

Though majority of the cases ( 8 cases-53\%) have history of smoking, a sizeable proportion of the cases (6 cases-40\%) do not have history of smoking. Thus, smoking cannot be conclusively observed as a contributing factor for death due to rupture of aortic dissection.

History of hypertension was observed in 8 cases (53\%), but 6 cases $(40 \%)$ did not have history of hypertension. History of hypertension was observed in 8 cases (89\%) among the age group above 40 years, but $1(11 \%)$ did not have history of hypertension. As majority of the cases above the age group of 40 was observed to have hypertension, it can be considered as a contributory factor for aortic dissection in that age group.

No history of aortic surgery was obtained in any of the cases. No history of cardiac catheterization/aortic ballooning was observed in all the cases. Arachnodactyly, polydactyly and xanthelasma were absent in all the cases. Corneal arcus present in $5(33 \%)$ cases and absent in $10(67 \%)$ cases.

Atherosclerosis was present in 11 (73\%) cases. Six cases $(40 \%)$ had atherosclerosis along with calcification. Four cases (27\%) showed atherosclerosis, calcification and hemorrhage into plaque. One case $(7 \%)$ showed ulceration along with hemorrhage into plaque. So atherosclerosis and complications of atherosclerosis are a major contributing factor for aortic dissection. 


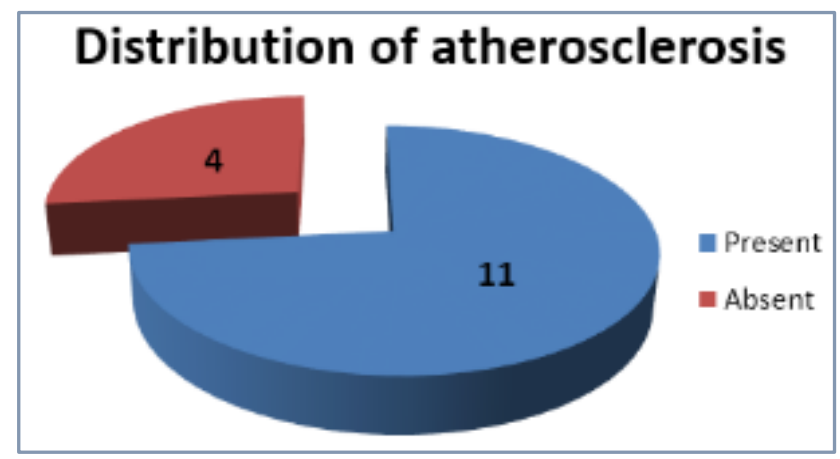

Fig. 3: Distribution of atherosclerosis among the study population

DeBakey classification of the cases showed that $4(27 \%)$ of death occurred due to Type I: (Intimal tear in ascending aorta, but which involves descending aorta as well) aortic dissection, $3(20 \%)$ of death was caused by Type II (Intimal tear limited to ascending aorta alone) and 8 (53\%) of the death was caused by Type III (Intimal tear is in the descending aorta with distal propagation of dissection) aortic dissection. That means majority of the death was due to Type III aortic dissection. In the age group $>40$ yrs, out of 10 cases, 8 were DeBakey Type III (80\%), and 2 were Type II. No case of Type I were reported in $>40$ yrs. age group. In the age group $<40$ yrs. of age out of total 5 cases 4 belonged to Type I (80\%) and one case was Type II. No case of Type III was reported in $<40$ yrs. age group.

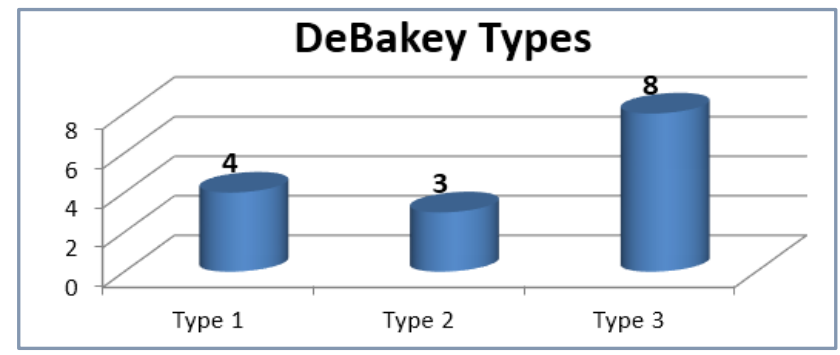

Fig. 4: Distribution of types of aortic dissection among the study population

Ascending aorta and arch of aorta were the sites of rupture in $(47 \%)$ cases respectively and in one case the aorta was not ruptured. Of the 15 cases, Cardiac Tamponade was present in $6(40 \%)$ cases and other $9(60 \%)$ cases cardiac tamponade was absent. Out of this 9 cases in which cardiac tamponade were absent 8 belonged to DeBakey type III and 1 case belonged to DeBakey type II, in which pericardium was found ruptured. In all the 6 cases in which cardiac tamponade were present belonged to either type I or II DeBakey.



Fig. 5: Distribution of cardiac tamponade among the study population
Weight of heart was less than $250 \mathrm{gm}$ in $1(7 \%)$ case, 250 to $340 \mathrm{gm}$ in $5(33 \%)$ cases, 340 to $400 \mathrm{gm}$ in $5(33 \%)$ cases, 400 to $500 \mathrm{gm}$ in $2(13 \%)$ cases and more than $500 \mathrm{gm}$ in $2(13 \%)$. Overweight of heart can be considered as a factor for aortic dissection.

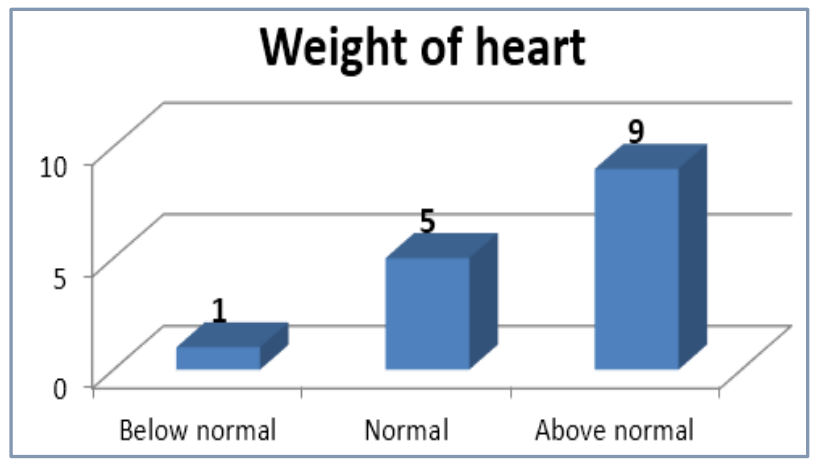

Fig: 6. Distribution of heart weight among study population

Left ventricular thickness is between 1 to $1.5 \mathrm{~cm}$ in $4(27 \%)$ cases, 1.5 to $2 \mathrm{~cm}$ in $7(47 \%)$ cases and more than $2 \mathrm{~cm}$ in $4(27 \%)$ cases. Out of this 15 cases, $11(73 \%)$ cases showed left ventricular hypertrophy which indicates there is a strong correlation between hypertrophy and aortic dissection. There was no case of mitral valve prolapse or aortic root dilatation observed among the sample population.

\section{Thickness of left ventricle}



Fig. 7: Distribution of left ventricular wall thickness among study population

\section{CONCLUSION}

Aortic dissection can affect all age groups, but more in the age group above 40 years of age. Age has a positive correlation in cases of death due to aortic dissection. Males were found to be more affected by it compared to females. Obesity is not a contributing factor for aortic dissection. Hypertension can be considered as a major contributory factor for aortic dissection as majority of the cases had hypertension. Atherosclerosis was present in a great majority of cases.

Majority of cases in the age group below 40 years of age, were DeBakey type I and in the age group above 40 years of age were type III. Cardiac tamponade was present in $40 \%$ of cases. All the cases in which cardiac tamponade was present belonged to either DeBakey type I or type II. Weight of heart was found to be more than normal in majority of the cases. Left ventricular hypertrophy was noted in the majority of cases. 


\section{BIBLIOGRAPHY}

1. Mark CA, Joseph L. Diseases of the Aorta. Harrison's Principles of Internal Medicine. 19 ed. Vol. 1. Ch 301 April 2015.

2. Khamdaengyodtai $P$, Terdtoon $P$, Sakulchangsatjatai $P$. Three-Dimension Stress and Strain Distributions across Five-Layer Human Aortic Wall. International Journal of Bioscience, Biochemistry and Bioinformatics, Vol. 3, No. 2, March 2013.

3. Efstratios A, Nikolaos BG, Miltiadis G. Acute Type-B Aortic Dissection: The Treatment Strategy. Hellenic J Cardiol 2010;51:338-347.
4. Deshmukh A, Deshmukh G. Aortic Dissection - A Case Report. Indian Journal of Public Health Research and development. Vol 4. Issue 1. 2013. P 69.

5. Nicki CR, Brian WR, Stewart RH. Diseases of the Aorta. Davidson's Principles and Practice of Medicine. 21 ${ }^{\text {st }}$ ed. 2010. P 603-605.

6. Vinay K, Abul AK, Nelson F, Jon AC, Robbins and Cotran. Pathologic Basis of Disease. 8 ${ }^{\text {th }}$ ed. 2010. P 508-510.

7. James JL, Eric IM, Rosella F, et al. Characterizing the Young Patient with Aortic Dissection: Results from the Internal Registry of Aortic Dissection. Journal of American College of Cardiology. Vol 43. No. 4. 2004. P.665-669. 